\title{
Education for Humanity
}

\author{
Jack T. Trevors • Milton H. Saier
}

Published online: 5 December 2009

(C) The Author(s) 2009. This article is published with open access at Springerlink.com

Humanity is facing nearly insurmountable challenges, risks, and crises. Resource depletion, global pollution of the entire biosphere, and climate change due to our excessive and uncontrollably growing human population may be the most difficult long-term problems that urgently need to be solved. However, the current influenza pandemic and other unforeseen but inevitable health emergencies including hunger, poverty, and a lack of universal public health infrastructure in the absence of stable country governments are common occurrences in our present world, and they will be increasingly problematic as our populations grow in a resource-depleted world. Conflicts including wars and terrorism, and a lack of reliable national and international leadership abetted by religious intolerance and corruption in governmental and religious institutions will contribute to the expected widespread failure of educational systems. Here, we shall address the causes and consequences of educational system failures, from elementary schools to universities.

Public support and governmental programs must provide the essential resources for scholarly and

\footnotetext{
J. T. Trevors $(\bowtie)$

School of Environmental Sciences, University of Guelph, Guelph, ON, Canada N1G 2W1

e-mail: jtrevors@uoguelph.ca

M. H. Saier $(\bowtie)$

Division of Biological Sciences, University of California at San Diego,

La Jolla, CA 92093-0116, USA

e-mail: msaier@ucsd.edu
}

successful schools, starting with K-12 and continuing up to our top universities. When education and research are not adequately supported by government funding, difficulties arise in all sectors of society, simply because knowledgeable people are not available to understand and interpret complex matters dealing with a community, a country, or the world. In fact, decision making that relies on irrational beliefs rather than knowledgeable understanding has a bleak future. Only education can provide logical assistance when formulating life's many strategies. The lack of it has arguably led to more personal and national disasters than any other source.

Most individuals in a society do not have the means to obtain a sufficient education so they can attempt to understand and contribute optimally to the world in which we live. If public support is lacking, only the rich can afford it, and $99 \%$ of the citizens, who are among those most likely to have the greatest problem-solving potential, will not receive it. Even for the wealthy, no educational system can achieve its maximal potential when it is under-resourced. Moreover, proper operation requires excellence in instructors, infrastructure, modern technologies/equipment, and enrolled students.

Educational institutions also require leadership, not just low-level administrative management. While numerous managers consider themselves leaders, those whom they manage know that this is too often simply wishful thinking. Individuals must assume responsibility when and where it is appropriate, but no further, in order to avoid poor educational performance resulting from excessive restrictions and inadequate training. 
Educational excellence must be a primary objective if humanity is ever to meet the many challenges that do and will continue to confront us. Our national and global problems demand highly knowledgeable people with advanced degrees in the humanities, science, medicine, agriculture, engineering, computing, business, and law. Strategies for solving challenges and identifying appropriate technologies must be correctly chosen and implemented by the most competent people or costly mistakes will result. An educated humanity is the key for teaching other people, including the next generation, how to understand the world we live in. Without it, there will be too many individuals who find themselves in a world they cannot understand. They will not even know how to gain knowledge and learning skills! They will lack the ability to peel back the complex layers of information to obtain the answers they need.

Let us use a current example to illustrate the importance of education. We are in the midst of the H1N1 influenza pandemic. How many countries have the capacity to produce vaccines and antiviral drugs to be administered to their citizens? Even the developed countries are finding it impossible to meet their goals. Yet, many developing countries do not have the capacity - or the funds-required to develop or obtain the vaccine and drugs. They are dependent on companies, countries, and the World Health Organization (WHO) who can provide these public health resources. Some countries, perhaps rightly, have other serious economic, political, human rights, and technological problems that hinder operation of a successful vaccine facility. Only with an educated populous, could such a country develop the means to deal with the unexpected.

Think of the thousands of other examples that require basic and advanced education. Knowledge that results from the achievement of advanced degrees is required for most other areas of human activities including agriculture, medicine, public health, communication, transportation, pollution control, birth control, financial regulation, international trade, diplomacy, conflict resolution, construction, manufacturing, alternative energy, and conservation. The list is endless. All countries need to recognize and accept the fact that education must be a priority and a human right. It is much more important than destructive religious conflicts and resource wars which can be avoided only through education.

Countries need to educate their citizens while providing basic human rights and the basic necessities of life. Education, free from religious dogma, will allow people to control and reduce the human population in a humane, strategic manner. Education will allow countries to develop the skills, expertise, and infrastructure to provide basic and more advanced needs for all humans. No modernized, industrialized country can function without a properly resourced educational system. Education is the basis for a successfully evolving humanity. An adequate educational system would allow individuals to consider the evolution of a modern, stable democratic state that contributes to humanity by assisting in dealing with major crises.

There are countries that have contributed little or nothing to humanity for centuries. They lack a stable form of governance, and basic human rights are violated regularly. An invitation might be extended on a continuous basis to their governmental leaders, offering them the opportunity to join humanity. Many will refuse, as they believe their way of governance is best. They are on the dark side, partly because they are not acting in a humane, democratic manner, but more often, because of their inadequate understanding. They do not provide educational opportunities because they themselves have not been educated. They do not understand its importance. They may never emerge from the dark ages.

Such "so-called leaders" will not succeed if they allow themselves to be governed by ancient and corrupt religious precepts, or if they operate as unprincipled self-serving dictators. In spite of occasional transient successes, they and their countrymen and women will not contribute appreciably to science, technology, or the humanities. They simply do not understand the world in which we live; they have not learned to identify with the greater good of humanity.

Education is the vehicle that can make the world a humane place for everyone. Education has as a priority objective the establishment and evolution of modern democracies. It can prevent one of the greatest of human tragedies. For satisfaction and happiness, we need to live in a world we can understand and contribute to. Ignorance may seem like bliss, but only for a very short period of time.

Open Access This article is distributed under the terms of the Creative Commons Attribution Noncommercial License which permits any noncommercial use, distribution, and reproduction in any medium, provided the original author(s) and source are credited. 